\title{
Effects of Aqueous Extract of Vigna unguiculata Seedlings Against Doxorubicin-Induced Cardiotoxicity and Kidney damage In Female Albino Rats
}

\author{
Olatunde A. Oseni*1, Ademola S. K. Idowu ${ }^{2}$ and Aminat Isah ${ }^{3}$ \\ ${ }^{1,2}$ Department of Medical Biochemistry, Faculty of Basic Medical Science, College of \\ Medicine, Ekiti-State University, Ado-Ekiti, Nigeria \\ ${ }^{3}$ Department of Science Laboratory Technology, Faculty of Science, Ekiti-State University, \\ Ado- Ekiti, Nigeria
}

\begin{abstract}
Doxorubicin is an anthracycline drug which is believed to cause immediate damage to myocardial cells by free radical generation in the cause of treatment of cancer. This study was however aimed to investigate the effects of the aqueous extract of the seedlings of Vigna unguiculata on heart, kidney as well as lipid profile disorders caused by this drug on female Wistar albino rats. Fifteen female Wistar albino rats were divided into three groups. Group 1 animals served as normal positive control; Group 2 animals served as negative control which were treated with $0.5 \mathrm{~mL}$ of $(20 \mathrm{mg} / \mathrm{kg}$ body weight doxorubicin) while Group 3 animals were treated with $0.5 \mathrm{~mL}$ each of $20 \mathrm{mg} / \mathrm{kg}$ body weight doxorubicin and $10 \%$ aqueous extract of seedlings of Vigna unguiculata. Some enzyme markers and lipid contents were determined. The results of the study showed an increase in the activities of plasma ALP and AST after treatment with the drug except in the heart for AST which showed a significant reduction, while treatment with the extract brought about a decrease in the plasma and the organs except for kidney AST. The ALT on the other hand showed slight increase in the plasma with a decrease in the kidney and heart after treatment with the drug as the treatment with the extract tend to restore it to the control in both cases, there was increased plasma and kidney but reduced heart HDL$C$ after treatment with the drug which was observed to be restored to control after treatment with extract in both situations. The triglyceride and total cholesterol did not show similar trend in the plasma and the studied organs. The LDL-C was also observed to be increased in both plasma and organs after the treatment with the drug which later reduced significantly towards the control after the administration of the sprout extract. The present study has shown that the doxorubicin has damaging effects on both kidney and heart tissues while the sprouts extract produce a restoration to the normal in both organs.
\end{abstract}

Keyword: Doxorubicin; cardiotoxicity; kidney damage; plant seedlings; chemoprotection.

\section{INTRODUCTION}

Doxorubicin is a secondary metabolite of Streptomyces peucetius var. Caesius, along with daunorubicin, epirubicin, and idarubicin, and belongs to the family of anthracyclines. These are well-established and highly effective anti-neoplastic agents, used to treat several adult and pediatric cancers, such as solid tumors, leukemia, lymphomas and breast cancer (Octavia et al., 2012). The successful use of doxorubicin has been hampered by toxicities such as hematopoietic suppression, 
nausea, vomiting, extravasation, and alopecia, yet the most feared side-effect is cardiotoxicity. The onset of this cardiotoxicity may be delayed until as many as 10-15 years after cessation of chemotherapy. It is characterized by a broad spectrum of symptoms ranging from asymptomatic electrocardiography (ECG)-changes, to pericarditis and decompensated cardiomyopathy (Octavia et al., 2012). While the probability of developing cardiomyopathy is largely dose-dependent (Allen, 1992) as cardiotoxicity may occur at low doses due to increased individual susceptibility (Jain, 2000).

Heart failure represents one of most important causes of death in developing and developed countries. Its high mortality originates in part from severe complications like cardiac contractile dysfunction and or sudden cardiac death caused by ventricular arrhythmias (Shin et al., 2007). Unfortunately, significant portion of heart failure stems from use and misuse of several drugs and medications. Indeed, the cardiac muscle is widely known as a target of injury for many drugs and many other chemical compounds. Following their cardiotoxic action, these could be divided into two relevant categories: i) drugs and cardiotoxic substances leading to heart failure in terms of abrupt contractile performance, and ii) drugs affecting ion channels or pumps and, in most cases, leading to prolongation of cardiac repolarization and to increased risk of severe cardiac arrhythmias and premature death. In some cases, it is very difficult to divide them into these categories as they may have both actions. Anthracyclines drugs like doxorubicin are believed to cause immediate damage to myocardial cells by free radical generation, although it may take months or years for this damage to become clinically apparent. However, it is not current practiced to always commence these medications in patients who have received cardiotoxic chemotherapy and are asymptomatic. Although several classification systems (Hunt, 2005; Brian et al., 2008 and Seidman et al., 2002) for heart failure severity have been established, a recent editorial proposed a new system for chemotherapy-related cardiac dysfunction (Ewer and Lippman, 2005). However, a recent retrospective analysis of breast cancer patients with doxorubicin-induced chronic heart failure CHF found that $87 \%$ improved with cardiac medications and that combined treatment with $\beta$ blockers, ACE inhibitors seemed superior to ACE inhibitors alone (Tallaj et al., 2005 and Brian et al., 2008). Retrospective reviews had initially reported mortality rates of $43 \%$ to $59 \%$ in patients who developed CHF after anthracycline drug treatment (Von Hoff et al., 1979. In a study of 38 patients (Ewer et al., 2005 and Brian et al., 2008), trastuzumab cardiotoxicity resolved on discontinuation of treatment with or without cardiac medications and did not always recur on rechallenge.

\section{MATERIALS AND METHOD}

\section{Sample collection and preparation}

\section{Plant material:}

Leguminous grains white beans (Vigna unguiculata) were bought from the Oja-Oba market in Ado-Ekiti, Ekiti State, Nigeria and were authenticated at Department of Plant Science, Ekiti State, University, Ado-Ekiti. The seeds were planted at a research garden in the university and the sprouts were obtained at the expiration of 4 weeks.

\section{Extract preparation:}

The seedlings were collected, air dried in the open laboratory and ground into powder with Marlex Excella laboratory blender which was kept for use. 
$10 \%$ aqueous extract of the seedlings was prepared for use in this study.

\section{Experimental protocol}

The study was performed on fifteen female Wistar albino rats housed in ventilated cages in the Animal House of College of Medicine, Ekiti State University, Ado-Ekiti, Nigeria. The animals were divided into three groups of five rats each. They were acclimatized for two weeks before administration of different dosages of drug and extracts.

There animals were grouped as follow:

- Group 1 Positive control animals without any treatment

- Group 2 Negative control animals (20mg/kg body weight doxorubucin drug intraperitoneally)

- Group 3 Treated animals (20mg/kg body weight doxorubucin drug intraperitoneally $+10 \%$ aqueous extract of Vigna unguiculata seedlings)

\section{Chemicals/Reagent kits}

All chemicals and drugs used were obtained commercially and of analytical grade. All the diagnostic kits are products of Fortress Chemical Ltd. England.

\section{Preparation of Organs homogenate}

The animals were quickly dissected; the blood was obtained for plasma and while heart and kidney were removed. $10 \%$ of each organ homogenate was then prepared in $6.7 \mathrm{mM}$ potassium phosphate buffer, ( $\mathrm{pH}$ 7.4) using hand held electric homogenizer. The homogenate was centrifuged at 6,000 rpm for 10 minutes at $4^{0} \mathrm{C}$ to obtain a clear supernatant which was stored at $8^{0} \mathrm{C}$ and used for measurement of biochemical contents.

\section{Biochemical Assay}

Fortress standard diagnostic kits were used in determination of Triglyceride (TG), Total cholesterol (TC), HDL-cholesterol (HDL-C), Total protein (TP), LDL-Cholesterol (LDL-C), Aspartate transaminase (AST), alkaline phosphatase (ALP) and Alanine transaminase (ALT).

\section{RESULTS AND DISCUSION}

The marker enzymes activities and some lipid status were measured to monitor the effects of this drug and treatment with the aqueous sprout extract in the plasma, kidney and heart of the albino rats. The observed significant increase $(p<0.05)$ in ALP activity in the plasma, kidney and heart of Group 2 (doxorubicin treated) compared with the control showed that the doxorubicin aggravated the activity of the enzyme in the plasma with concomitant increase in the organs enzyme activities which suggest organs damage when compared with the control. This may be attributable to loss of membrane components due to a possible reaction between doxorubicin and the tissues (Table 4.1). Therefore, enzymes from diseased organs may become manifested in the plasma resulting in increased activity since they must have leaked from the diseased organ. The increased activity of the plasma enzyme is often accompanied by a corresponding decrease in enzyme activity of the affected organ though the reverse is the case in this study as the activities of the enzymes in the organs appeared slightly higher than the plasma. However, there was a pronounced reduction in ALP activities in the plasma and the organs as seen in Group 3 that was treated with aqueous extract of seedlings of Vigna unguiculata which is attributed to the protective effect of the plant. 
Table 4.1: Effects of aqueous extract of seedlings of Vigna unguiculata on Doxorubicin- induced tissues damage on specific activity of Alkaline Phosphatase in Female Wistar Albino rats.

\begin{tabular}{|c|c|c|c|}
\hline \multicolumn{5}{|c|}{ ALP (U/L) } \\
\hline GROUP & PLASMA & KIDNEY & HEART \\
\hline 1 & $6.46 \pm 0.07^{\mathrm{a}}$ & $10.13 \pm 0.10^{\mathrm{a}}$ & $12.16 \pm 0.07^{\mathrm{a}}$ \\
\hline 2 & $15.86 \pm 0.36^{\mathrm{c}}$ & $17.06 \pm 0.08^{\mathrm{b}}$ & $17.95 \pm 0.14^{\mathrm{b}}$ \\
\hline 3 & $10.23 \pm 0.07^{\mathrm{b}}$ & $10.64 \pm 0.07^{\mathrm{a}}$ & $16.19 \pm 0.07^{\mathrm{c}}$ \\
\hline
\end{tabular}

The transaminases (AST and ALT) are biomarkers to predict possible toxicity (Rahman et al., 2001).

Furthermore, measurement of enzymatic activities of AST and ALT is of clinical and toxicological importance as changes in their activities are indicative of heart damage. Just as observed in the liver damage by toxicants or in diseased conditions (Singh et al., 2001).

Table 4.2: Effects of aqueous extract of seedlings of Vigna unguiculata on Doxorubicin- induced tissues damage on specific activity of Aspartate Transaminase in Female Wistar Albino rats.

\begin{tabular}{|c|c|c|c|}
\hline \multicolumn{5}{|c|}{ AST(U/L) } \\
\hline GROUP & PLASMA & KIDNEY & HEART \\
\hline 1 & $37.77 \pm 2.03^{\mathrm{a}}$ & $32.11 \pm 3.103^{\mathrm{a}}$ & $120.56 \pm 18.90^{\mathrm{b}}$ \\
\hline 2 & $56.96 \pm 5.28^{\mathrm{b}}$ & $33.87 \pm 2.40^{\mathrm{ab}}$ & $68.07 \pm 8.94^{\mathrm{a}}$ \\
\hline 3 & $50.67 \pm 8.35^{\mathrm{b}}$ & $35.11 \pm 6.76^{\mathrm{b}}$ & $64.86 \pm 7.88^{\mathrm{a}}$ \\
\hline
\end{tabular}

In the present study, the observed increase in the activities of plasma AST and ALT suggests that there may be a leakage of these enzymes from the studied organs, thereby causing an increase in the level of the enzymes in the plasma. However, there is evidence of restoring the activities of these enzymes to normal in group 3 (Tables 2 and 3) after treatment with the extract of the sprout. There are therefore evidences of possible damage to the kidney and heart of rat caused by the drug and the restoring power of the extract of sprout of this edible leguminous plant.

Our findings however corroborate the observations of other researchers like Oluduro and Aderiye, (2009) in their work on effect of Moringa oleifera seed extract on vital organs.

Table 4.3: Effects of aqueous extract of seedlings of Vigna unguiculata on Doxorubicin- induced tissues damage on specific activity of Alkaline Transaminase in Female Wistar Albino rats.

\begin{tabular}{|c|c|c|c|}
\hline \multicolumn{5}{|c|}{ ALT(U/L) } \\
\hline GROUP & PLASMA & KIDNEY & HEART \\
\hline 1 & $16.98 \pm 0.09^{\mathrm{a}}$ & $39.67 \pm 0.05^{\mathrm{b}}$ & $49.51 \pm 0.05^{\mathrm{b}}$ \\
\hline 2 & $17.98 \pm 0.28^{\mathrm{b}}$ & $26.37 \pm 0.11^{\mathrm{a}}$ & $33.60 \pm 0.05^{\mathrm{a}}$ \\
\hline 3 & $15.55 \pm 0.10^{\mathrm{a}}$ & $38.26 \pm 0.20^{\mathrm{b}}$ & $55.18 \pm 0.05^{\mathrm{c}}$ \\
\hline
\end{tabular}


tissue enzymes activities of male albino rats and Udoh et al., (2011) in effect of alkaloids extract of Gnetum africanum on serum enzymes levels in albino rats as well as Oseni et al., (2015) in inhibitory activity of ethanolic extract of horseradish (Moringa oleifera) (Lam) on oxidative stress parameters in some organs of dexamethazone induced hypertensive Wistar rats.
Intra-peritoneal administration of doxorubicin caused significant reductions in the concentrations of triglyceride in plasma, kidney and heart (Table 4.4). The extract of the sprout then caused significant and progressive elevation in of triglyceride concentrations in the plasma and tissues as seen in Group 3 after the animals were treated with the extract.

Table 4.4: Effects of aqueous extract of seedlings of Vigna unguiculata on Doxorubicin- induced tissues damage on Triglyceride (TRG) concentration in Female Wistar Albino rats.

\begin{tabular}{|c|c|c|c|}
\hline \multicolumn{3}{|c|}{ TRG $(\mathbf{m m o l} / \mathbf{d l})$} \\
\hline GROUP & PLASMA $^{\text {KIDNEY }}$ & HEART \\
\hline 1 & $1.24 \pm 0.02^{\mathrm{b}}$ & $2.00 \pm 0.03^{\mathrm{b}}$ & $2.57 \pm 0.04^{\mathrm{b}}$ \\
\hline 2 & $0.87 \pm 0.01^{\mathrm{a}}$ & $1.90 \pm 0.01^{\mathrm{a}}$ & $1.76 \pm 0.04^{\mathrm{a}}$ \\
\hline 3 & $2.37 \pm 0.01^{\mathrm{c}}$ & $1.99 \pm 0.11^{\mathrm{a}}$ & $1.98 \pm 0.12^{\mathrm{a}}$ \\
\hline
\end{tabular}

Significant elevation of LDL-CHL was observed after administration of doxorubicin in the plasma and the tissues which can increase the rate of deposition of cholesterols and other lipids into the blood vessels and the organs, which will eventually results in atherosclerosis and other related disease. The treatment with the aqueous extract of seedlings of Vigna unguiculata in Group 3 however reduced significantly the concentration LDL-cholesterol in both the plasma and the studied tissues, which then explained the chemoprotective potential of the extract to restore the effects of the drug to near control.

Table 4.5: Effects of aqueous extract of seedlings of Vigna unguiculata on Doxorubicin- induced tissues damage on LDL-cholesterol concentration in Female Wistar Albino rats.

\begin{tabular}{|c|c|c|c|}
\hline \multicolumn{3}{|c|}{ LDL (mmol/I) } \\
\hline GROUP & PLASMA & KIDNEY & HEART \\
\hline 1 & $0.78 \pm 0.16^{\mathrm{a}}$ & $1.58 \pm 0.32^{\mathrm{a}}$ & $0.447 \pm 0.000^{\mathrm{a}}$ \\
\hline 2 & $4.25 \pm 0.63^{\mathrm{b}}$ & $3.36 \pm 0.63^{\mathrm{b}}$ & $1.559 \pm 0.158^{\mathrm{b}}$ \\
\hline 3 & $1.34 \pm 0.12^{\mathrm{a}}$ & $1.67 \pm 0.15^{\mathrm{a}}$ & $5.143 \pm 1.265^{\mathrm{c}}$ \\
\hline
\end{tabular}

The observed significant reduction in the cardiac concentrations of total cholesterol and HDLcholesterol fractions could also be due to depressed hepatic gluconeogenesis by the drug, although this claim remains a speculation until it is subjected to further scientific validation by the key enzymes regulating this pathway. A positive relationship between gluconeogenesis and lipogenesis has been well documented in literature (Harris and Crabbs, 1982). Any drug that interferes with gluconeogenesis has also been reported to also interfere with lipogenesis in a previous study. 
Table 4.6: Effects of aqueous extract of seedlings of Vigna unguiculata on Doxorubicin-induced tissues damage on HDL-cholesterol concentration in Female Wistar Albino rats.

\begin{tabular}{|c|c|c|c|}
\hline \multicolumn{3}{|c|}{ HDL (mmol/dl) } \\
\hline GROUP & PLASMA & KIDNEY & HEART \\
\hline 1 & $3.91 \pm 0.15^{\mathrm{a}}$ & $2.72 \pm 0.06^{\mathrm{a}}$ & $3.11 \pm 0.03^{\mathrm{b}}$ \\
\hline 2 & $7.54 \pm 0.12^{\mathrm{b}}$ & $8.58 \pm 0.15^{\mathrm{b}}$ & $1.68 \pm 0.06^{\mathrm{a}}$ \\
\hline 3 & $4.88 \pm 0.06^{\mathrm{a}}$ & $4.52 \pm 0.05^{\mathrm{c}}$ & $3.85 \pm 0.01^{\mathrm{b}}$ \\
\hline
\end{tabular}

The observed increase in the HDL-cholesterol concentration in the plasma and kidney after the introduction of the drug and the reduction of cardiac total cholesterol and triglycerides reported in this work may be owing to the drug interfering with their biosynthesis (Table 4.6). However, the sprout extract restorations of the concentrations of these compounds nearly to control in both cases indicate its medicinal importance.
Apart from the plasma that showed a significant increase in the total cholesterol concentration after the drug administration (Table 4.7), there were significant reductions in the concentrations of this compound in the studied organs. The administration of the aqueous extract of sprout of Vigna unguiculata however could not produce any significant change in the concentrations of total cholesterol in both plasma and the tissues under investigations.

Table 4.7: Effects of aqueous extract of seedlings of Vigna unguiculata on Doxorubicin-induced tissues damage on Total Cholesterol level in Female Wistar Albino rats

\begin{tabular}{|c|c|c|c|}
\hline \multicolumn{5}{|c|}{$(\mathbf{m m o l} / \mathbf{l})$} \\
\hline GROUP & PLASMA & KIDNEY & HEART \\
\hline 1 & $3.67 \pm 0.04^{\mathrm{a}}$ & $4.40 \pm 0.05^{\mathrm{b}} \pm 0.02^{\mathrm{b}}$ \\
\hline 2 & $4.07 \pm 0.02^{\mathrm{b}}$ & $3.46 \pm 0.06^{\mathrm{a}}$ & $3.69 \pm 0.04^{\mathrm{a}}$ \\
\hline 3 & $4.18 \pm 0.02^{\mathrm{b}}$ & $3.85 \pm 0.03^{\mathrm{ab}}$ & $3.81 \pm 0.02^{\mathrm{a}}$ \\
\hline
\end{tabular}

From the above observations, it can then be suggested that administration of doxorubicin at dose level of $20 \mathrm{mg} / \mathrm{kg}$ body weight could induce oxidative stress in both heart and kidney by altering the activities of some important biomarker enzymes such Aspartate transaminase, Alkaline Transaminase, Alkaline phosphatase and lipid contents such as Triglyceride, HDL-cholesterol concentration, LDL-cholesterol concentration and total cholesterol, thereby being responsible for the initiation of kidney damage, coronary heart disease and possibly atherosclerosis with the extract response with intention of reducing the effects to the almost levels of the control.

\section{CONCLUSSION AND RECOMMENDATION}

Doxorubicin is a potent nephrotoxic and cardiotoxic agents as it enhances the significant reduction in the concentrations of kidney and heart lipid status. It also caused cardiac dysfunction as revealed in marked increase in cardiac AST, ALP and reduction in ALT. The present study has also shown that at 
$20 \mathrm{mg} / \mathrm{kg}$ body weight doxorubicin, serious damaging effects was provoked on both kidney and heart cells. Therefore usage of this drug without expert prescription may result in severe kidney and heart problems and as such should be avoided.

This preliminary study has been able to demonstrate the nephrotoxic and cardiotoxic effects of doxorubicin and chemoprotective potential of aqueous extract of the sprout of the cowpea against doxorubicin-induced toxicity in female rats. The study also shows the chemopreventive benefit of the extract on doxorubicin-induced oxidative damage in female rats as they significantly reduced the extent of biomarker enzymes loss and restoration of toxicity caused by doxorubicin. However, the study revealed the protective effect of the aqueous extract of seedlings of Vigna unguiculata on Doxorubicininduced tissues damage, which can be exploited for medicinal purposes. Additional investigations can still be conducted on the extent of action of the extract.

\section{REFERENCES}

1) Allen, A. (1992). The cardiotoxicity of chemotherapeutic drugs. Semin Oncol.; 19: 529-542.

2) Brian, R. J. Healey, B., Sandra, M. S. (2008). 'Cardiac Toxicity in Breast Cancer Survivors: Review of Potential Cardiac Problems'. Clin Cancer Res., 14; 14.

3) Ewer, M.S., Lippman, S. M. (2005). Type II Chemotherapy-related cardiac dysfunction: time to recognize a new entity. J Clin Oncol; 23:2900-2.

4) Harris, R.A., Crabb, D.W. (1982). Metabolic interrelationships. In: Textbook of
Biochemistry with Clinical Correlations, Ed. Delvin TM, New York: John Wiley and Sons Inc., pp: 531-559.

5) Hunt, S. A., Abraham, W.T., Chin, M.H. (2005) Guideline update for the diagnosis and management of chronic heart failure in the adult: a report of the American College of Cardiology/American Heart Association Task Force on Practice Guidelines. Circulation; 112: 154-235.

6) Jain, D. (2000). Cardiotoxicity of doxorubicin and other anthracycline derivatives. J Nucl Cardiol.; 7: 53-62.

7) Octavia, Y., Tocchetti, C. G., Gabrielson, K. L., Janssens, S., Crijins H. J., Moens, A. L. (2012). Doxorubicin-induced cardiomyopathy: From molecular mechanisms to therapeutic strategies. Journal of Molecular and Cellular Cardiology. Volume 52, Issue 6, Pages 1213-1225.

8) Oluduro, A. O. and Aderiye, B. I. (2009). Effect of Moringa oleifera seed extract on vital organs and tissue enzymes activities of male albino rats. African Journal of Microbiology Research Vol. 3(9) pp. 537540.

9) Oseni, O. A., Idowu A. S. K., Obaparus, T. O. (2015). Inhibitory Activity of Ethanolic Extract of Horseradish (Moringa oleifera) (Lam) on Oxidative Stress Parameters in Some Organs of Dexamethazone Induced Hypertensive Wistar Rats. International Journal of Biochemistry Research \& Review 8(4): 1-10, 
10) Rahman, M. F., Siddiqui, M. K., Jamil, K., 2001. Effects of vepacide (Azadirachta indica) on aspartate and alanine aminotransferase profiles in sub-chronic study with rats. J. Hum.Exp. Toxicol. 20, 243-249.

11) Seidman, A., Hudis, C., Kathryn, P. M. (2002). Cardiac dysfunction in the trastuzumab Clinical trials experience. J Clin Oncol; 20:1215-21.

12) Shin, D.D., Brandimarte F., De Luca, L., Sabbah, H.N., Fonarow, G.C, Filippatos G, Komajda M, Gheorghiade M. (2007). Review of current and investigational pharmacologic agents for acute heart failure syndromes. Am J Cardiol.; 99:4A-23A.

13) Singh, N.S., Vats, P., Suri, S., Shyam, R., Kumria, M.M.L., Ranganathan, S., Sridharan, K., 2001. Effect of an antidiabetic extract of Catharanthus roseus on enzymic activities in streptozotocin induced diabetic rats. J. Ethnopharmacol. 76, 269-277.

14) Tallaj JA, Franco V, Rayburn BK, et al. Response of doxorubicin-induced cardiomyopathy to the current management strategy of heart failure. J Heart Lung Transplant 2005; 24:2196-201.

15) Udoh, F. V., Ekanem, A. P., Ebong, P. E. (2011). Effect of alkaloids extract of Gnetum africanum on serum enzymes levels in albino rats. Journal of Applied Pharmaceutical Science 01 (09); 2011: 2932

16) Von Hoff, D.D., Layard, M.W., Basa, P., Davis, H. L., Von Hoff. A.L., Rozencweig.
M, Muggia FM. (1979). Risk factors for doxorubicin-induced congestive heart failure. Ann Intern Med.; 91: 710-717. 